\title{
Extraction of Metal Ions Using Chemically Modified Silica Gel Covalently Bonded with 4,4'-Diaminodiphenylether and 4,4'- Diaminodiphenylsulfone-salicylaldehyde Schiff Bases
}

\author{
R. K. DeY, ${ }^{* \dagger}$ Usha JHA,* A. C. Singh,* S. SAMAL, $* *$ and Alok R. RAY*** \\ *Department of Applied Chemistry, Birla Institute of Technology, Mesra-835 215, Ranchi, India \\ **Department of Material Science and Engineering, K-JIST, 1, Oryong Dong, Buk-gu, South Korea \\ ***Centre for Biomedical Engineering, Indian Institute of Technology, New Delhi-110 016, India
}

\begin{abstract}
Two new chelating materials (Si-DDE- $o$-HB, and Si-DDS- $o$-HB) were synthesized by modifying the activated silica gel phase with Schiff bases of 4,4'-diaminodiphenylether (DDE)/4,4'-diaminodiphenylsulfone (DDS) and $o$ hydroxybenzaldehyde $(o-\mathrm{HB})$. The synthesized materials were characterized by FTIR and BET surface area measurement techniques. The extraction of metal ions such as $\mathrm{Zn}^{2+}, \mathrm{Mn}^{2+}$ and $\mathrm{Cr}^{3+}$ by the chelating material Si-DDE- $o$ $\mathrm{HB}$ was found to be higher than that by Si-DDS- $o-\mathrm{HB}$. The order of metal sorption was found to be $\mathrm{Zn}^{2+}>\mathrm{Mn}^{2+}>\mathrm{Cr}^{3+}$. The correlation coefficients for Freundlich and Langmuir adsorption isotherms were compared for the sorption of $\mathrm{Zn}^{2+}$ onto the chelating material. The loading and elution of the metal ion solution was examined at optimum $\mathrm{pH} 7.5$ and 0.5 $\mathrm{cm}^{3} \mathrm{~min}^{-1}$ flow rate of the solution using a column technique. The preconcentration factor for the elution of $\mathrm{Zn}^{2+}$ using dilute $\mathrm{HNO}_{3}$ was found to be 66.2 with a breakthrough volume of $15 \mathrm{~cm}^{3}$. The data obtained for the preconcentration of $\mathrm{Zn}^{2+}$ by the column technique suggested that the material Si-DDE-o-HB can find industrial applications.
\end{abstract}

(Received January 16, 2006; Accepted April 12, 2006)

\section{Introduction}

Silica gel is an amorphous inorganic polymer containing an internal siloxane group $(\mathrm{Si}-\mathrm{O}-\mathrm{Si})$ with silanol groups $(\mathrm{Si}-\mathrm{OH})$ distributed on the surface. ${ }^{1,2}$ It is commonly used as a rigid matrix for ligand immobilization. ${ }^{3}$ The chemical modification of silica gel surfaces with donor atoms such as $\mathrm{N}, \mathrm{S}, \mathrm{O}$ and $\mathrm{P}$ is primarily aimed at improving the adsorption and exchange properties of the silica gel along with incorporation of the particular selective characteristics into the modified silica gel phases towards certain metal ions. ${ }^{4}$ The immobilization of chelating materials containing donor atoms on the silica gel surface can occur via chemical bond formation between organic modifiers like amino or chloro modified silica gel phases or through simple physical adsorption processes. ${ }^{5}$ Such a process often incorporates selectivity in synthesized materials. ${ }^{6,7}$ Several new chemically modified silica gels were synthesized, and applied as normal or selective solid phase extractor for many toxic and other metal ions. They were found to be superior to the conventional ion exchange resins in their ability to extract and selectively preconcentrate the heavy metal ions from solutions containing high concentrations of alkali and alkaline earth metal ions. ${ }^{8-10}$ Advantages of the modified solid phase extractors compared with the classical liquid extractor's were reported in many references. ${ }^{11,12}$

Schiff bases, having multidentate coordination sites, are known to form complexes with transition metal ions readily. ${ }^{13,14}$ The Schiff bases derived from salicylaldehyde (Salens) as

$\dagger$ To whom correspondence should be addressed. E-mail: rkdey@ rediffmail.com polydentate ligands are known to form stable complexes with transition metal ions..$^{15,16}$

The present work describes the syntheses of two new chemically modified silica gel covalently bonded with $4,4^{\prime}$ diaminodiphenylether and 4,4'-diaminodiphenylsulfonesalicylaldehyde Schiff bases. The synthesized chelating materials were used for the preconcentration and separation of $\mathrm{Cr}^{3+}, \mathrm{Zn}^{2+}$, and $\mathrm{Mn}^{2+}$ from dilute aqueous solutions. They were compared to determine their metal binding, extraction and selective abilities using batch techniques. The more reactive chelating material, Si-DDE-o-HB, was utilized in a column technique for the preconcentration of $\mathrm{Zn}^{2+}$ and $\mathrm{Cr}^{3+}$. Elution of the sorbed cations in column experimental studies provided an example of using the chelating material in continuous cycle operation and recovery of the metal ions. The analytical precision and accuracy of the result were tested with satisfactory results, and the method was found to be rapid, precise, simple and convenient to use.

\section{Experimental}

\section{Apparatus}

The specific surface areas of the dry silica and loaded silica were determined by BET method on NOVA 1000, high speed gas sorption analyzer, Quantachrome Corporation, USA. A Shimadzu atomic absorption spectrophotometer (Model AA680) equipped with a single element hollow cathode lamp and an air-acetylene burner was used for the estimation of metal ions. The instrument parameters were those recommended by the manufacturer. The wave lengths $(\mathrm{nm})$ selected for the analytes were as follows: $\mathrm{Mn}(279.5 \mathrm{~nm}), \mathrm{Cr}(357.9 \mathrm{~nm})$, and 


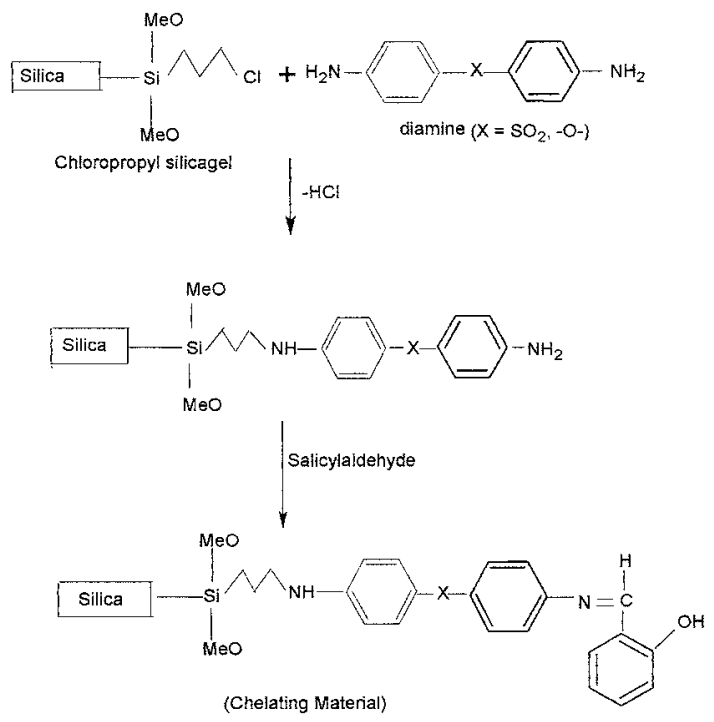

Scheme 1 Reaction scheme.

Zn $(213.9 \mathrm{~nm})$. The FTIR spectra were recorded in a Perkin Elmer 1800 Model. The $\mathrm{pH}$ values of sample solutions were determined by a Systronic digital $\mathrm{pH}$ meter Model 335 equipped with a combined glass calomel electrode for $\mathrm{pH}$ adjustment.

\section{Reagents}

The starting materials such as 3-chloropropyltrimethoxysilane, $o$-hydroxybenzaldehyde $(o$-HB $), \quad 4,4^{\prime}$-diaminodiphenylether (DDE), 4,4'-diaminodiphenylsulfone (DDS) were from Merck; they were used without further purification. All other chemicals and solvents (AnalR/GR grade, Merck or BDH, India) were used as received. Silica gel $(70-230$ mesh) was purchased from SRL, India.

Double distilled deionized water (DDW) was used for the preparation of solutions, wherever required. Standard solutions of AAS grade $\mathrm{Cr}, \mathrm{Zn}$ and $\mathrm{Mn}(\mathrm{CDH}$, India) were used for the preparation of calibration curves in the atomic absorption spectrophotometer. The estimation of metal ions was done according to the reported standard procedure. ${ }^{17}$ The buffers used to control the $\mathrm{pH}$ of the solution were $\mathrm{HCl} / \mathrm{KCl}$, $\mathrm{Na}_{3} \mathrm{PO}_{4} / \mathrm{H}_{3} \mathrm{PO}_{4}$, and $\mathrm{Na}_{3} \mathrm{PO}_{4} / \mathrm{NaOH}$. Solutions of $\mathrm{Cr}^{3+}, \mathrm{Mn}^{2+}$ and $\mathrm{Zn}^{2+}$ were prepared from suitable reagent grade nitrate or chloride salts by dissolving in DDW.

\section{Chemical modification of silica gel}

Silica gel $(70-230$ mesh) was used as the supporting material. Silica gel was refluxed with $6 \mathrm{~N} \mathrm{HCl}$ for $4 \mathrm{~h}$ to remove iron, if present, and was made acid-free by washing several times with DDW and checking the $\mathrm{pH}$ of the washing. The conditioned silica, after drying, was sieved by mechanical sieves and the fraction of the mesh size 100 - 120 was collected. The activated silica, thus obtained, was filtered, washed with ethanol and dried at $90-110^{\circ} \mathrm{C}$ for $24 \mathrm{~h}$. Approximately $50 \mathrm{~g}$ of activated dry silica was immersed in a mixture consisting of $100 \mathrm{~cm}^{3}$ of anhydrous xylene and $10 \mathrm{~cm}^{3}$ of 3-chloropropyltrimethoxysilane to produce 3-chloropropylsilica gel (Si-Cl). The mixture was refluxed under continuous stirring, with careful protection against moisture. Unreacted silanes were extracted with xylene and hexane in a Soxhlet apparatus. After this operation, the silica is subjected to drying under vacuum and then to an end-capping reaction with hexamethyldisilazane in order to deactivate the free silanol groups remaining on the silica surface. ${ }^{18}$

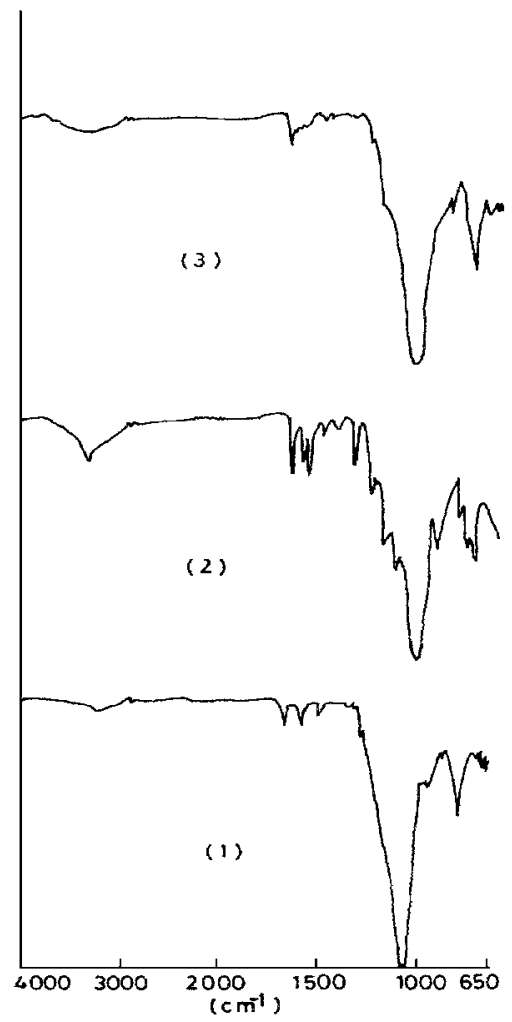

Fig. 1 FTIR spectra of silica gel (1), organochloro functionalized silica gel (2), and Si-DDE- $o$-HB (3).

Synthesis of chelating materials Si-DDS-o-HB and Si-DDE-o$H B$

The synthesis procedure is given in Scheme 1. Fifty grams of the above 3-chloropropylsilica gel $(\mathrm{Si}-\mathrm{Cl})$ were immersed in $200 \mathrm{~cm}^{3}$ of methanol and reacted with $2.64 \mathrm{~g}(10 \mathrm{mmol})$ of 4,4'diaminodiphenylsulfone (DDS) under reflux condition, in the presence of $0.05 \mathrm{~g}$ of $\mathrm{CaCO}_{3}$ for nearly $5 \mathrm{~h}$. The product ( $\mathrm{Si}-$ DDS) so formed was filtered, washed thoroughly with methanol and dried in vacuo at $60-70^{\circ} \mathrm{C}$. In the subsequent step, $40 \mathrm{~g}$ of the product $\mathrm{Si}$-DDS was made to react with $o$ hydroxybenzaldehyde $(o-\mathrm{HB})\left(5 \mathrm{~cm}^{3}, 0.6 \mathrm{mmol}\right)$ to yield the respective Schiff base, which was the desired chelating material Si-DDS-o-HB. The color of the chelating material was yellowish brown. The material was filtered off, washed with methanol, and dried in vacuo at $60-70^{\circ} \mathrm{C}$. Following a similar procedure, the other chelating material Si-DDE- $o$-HB was synthesized. The color of the chelating material was found to be reddish brown.

\section{Analytical studies}

The metal ion uptake studies were carried out by both batch and column techniques. The adsorption capacity $\left(Q, \mathrm{mmol} \mathrm{g}^{-1}\right)$, the distribution ratio $\left(D, \mathrm{~cm}^{3} \mathrm{~g}^{-1}\right)$, and the selectivity factor $(\alpha)$ were calculated according to the following equations:

$$
\begin{aligned}
& Q=\left(C_{\mathrm{o}}-C_{\mathrm{e}}\right) V / m \\
& D=Q / C_{\mathrm{e}} \\
& \alpha=D_{1} / D_{2}
\end{aligned}
$$

Here, $C_{\mathrm{o}}$ and $C_{\mathrm{e}}$ are the initial concentration and final concentration of metal ions $\left(\mathrm{mmol} \mathrm{dm}^{-3}\right)$ at equilibrium, 


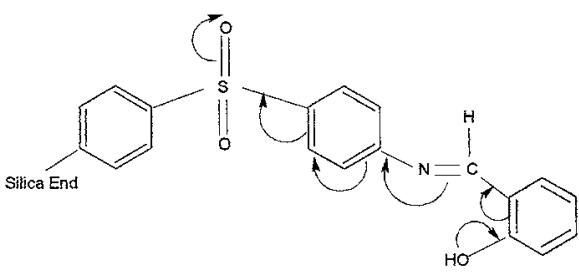

Scheme 2 Electron shifting in DDS unit.

respectively. $V$ is the volume of the solution in $\mathrm{dm}^{3}$, and $m$ is the mass of the chelating materials, $D_{1}$ and $D_{2}$ refer to the distribution ratios of metal ion 1 and metal ion 2, respectively.

\section{Results and Discussion}

\section{Characterization by FTIR}

Analysis of the FTIR spectra (Fig. 1) of the activated silica gel and the organofunctionalized silica gel shows the presence of $\mathrm{Si}-\mathrm{O}-\mathrm{Si}$ at around $1050 \mathrm{~cm}^{-1}$ and a band at $3200-3400 \mathrm{~cm}^{-1}$ corresponding to the silanol group and adsorbed water molecules. Peaks around 1440, 1410, and $1356 \mathrm{~cm}^{-1}$ are assigned to deformation modes of the $-\mathrm{CH}_{2}$-group generated from an organofunctionalized compound. The peak that appeared at about $1560 \mathrm{~cm}^{-1}$ was assigned to deformation mode $\delta(\mathrm{NH})$ of $-\mathrm{CNH}-$ moiety from organofunctionalized silica gel material. The peak that appeared at $1660 \mathrm{~cm}^{-1}$ was assigned to the $\delta(\mathrm{OH})$ of the matrix. The peak that appeared at around 900 and $675 \mathrm{~cm}^{-1}$ characterize the presence of the aromatic group in the unit (Si-DDS and Si-DDE). The presence of N-H stretch $(\mathrm{H}$ bonded) at 3372 and $3290 \mathrm{~cm}^{-1}$ and the C-N stretch at around $1071 \mathrm{~cm}^{-1}$ characterizes the presence of amine groups in the chelating material. The peak appeared at $1620 \mathrm{~cm}^{-1}$ assigned to $\mathrm{C}=\mathrm{N}$ in Si-DDE- $o$-HB. These spectral changes confirmed that the organic group is bound to the silica surface.

\section{Surface coverage value in silica gel}

The surface area coverage value was obtained by BET surface area measurement technique. The specific surface areas for the activated dry silica (sample density $0.9447 \mathrm{~g} \mathrm{~cm}^{-3}$ ), and for the loaded silica surface (Si-DDE-o-HB, sample density $0.9725 \mathrm{~g}$ $\mathrm{cm}^{-3}$ ), were examined to obtain the surface area coverage value. The specific surface areas were found to be 486.798 and 41.814 $\mathrm{m}^{2} \mathrm{~g}^{-1}$ for dry silica and loaded silica surface, respectively. Such a large decrease in surface area may be attributed to the blocking of pores by the ligands present at the surface, as a result of which nitrogen can not enter into the pore, resulting in a considerable decrease in the surface area. Embedded ligands also contribute to the decrease of the surface area of the substance. ${ }^{18}$

\section{Analytical studies}

The effect of contact time upon the sorption of the metal ions from aqueous solution was investigated in batch experiments. The amount of the metal ions sorbed per unit mass of the chelating materials was increased with the increase in contact time period (Fig. 2). The saturation (plateau value) in each curve was obtained within a period of $30 \mathrm{~min}$ for $\mathrm{Zn}^{2+}$ and $\mathrm{Mn}^{2+}$ However, the sorption of $\mathrm{Cr}^{3+}$ required nearly $3 \mathrm{~h}$. For both the chelating materials, the order of sorption of the metal ions was found to be $\mathrm{Zn}^{2+}>\mathrm{Mn}^{2+}>\mathrm{Cr}^{3+}$. Comparing the sorption capacity of the chelating materials, Si-DDS- $o$-HB and Si-DDE-

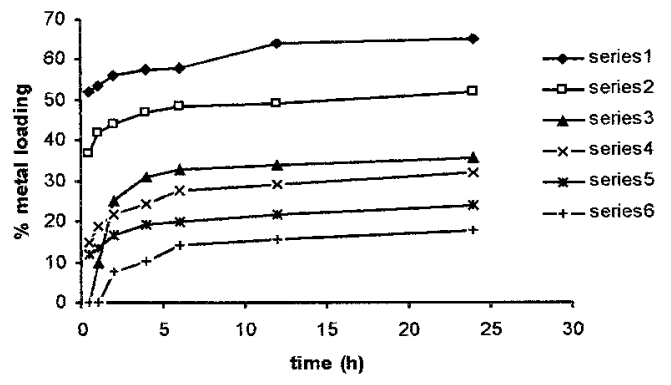

Fig. 2 Effect of contact time variation. For Si-DDE- $o$-HB: series $1, \mathrm{Zn}^{2+} ; 2, \mathrm{Mn}^{2+} ; 3, \mathrm{Cr}^{3+}$. For Si-DDS-o-HB, series $4, \mathrm{Zn}^{2+} ; 5, \mathrm{Mn}^{2+}$ $6, \mathrm{Cr}^{3+}$. Amount of chelating materials, $500 \mathrm{mg}$; concentration of the solution, $100 \mathrm{mg} \mathrm{dm}^{-3}$; $\mathrm{pH}$, neutral; total volume of the solution, 20 $\mathrm{cm}^{3}$; temperature, $28 \pm 2^{\circ} \mathrm{C}$.

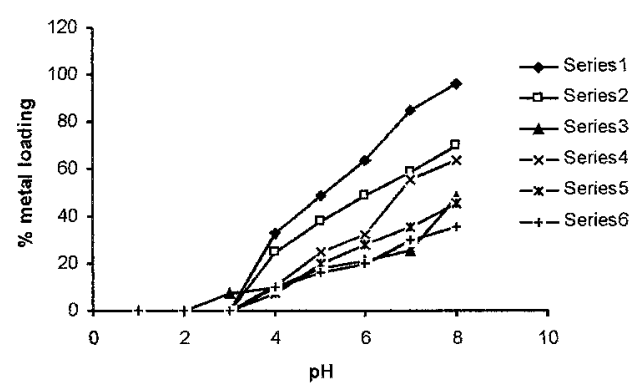

Fig. 3 Effect of $\mathrm{pH}$ of the medium. For Si-DDE-o-HB: series 1, $\mathrm{Zn}^{2+} ; 2, \mathrm{Mn}^{2+} ; 3, \mathrm{Cr}^{3+}$. For Si-DDS-o-HB: series 4, $\mathrm{Zn}^{2+} ; 5, \mathrm{Mn}^{2+} ; 6$, $\mathrm{Cr}^{3+}$. Amount of materials, $500 \mathrm{mg}$; concentration of the solution, $100 \mathrm{mg} \mathrm{dm}^{-3}$; total volume of the solution, $20 \mathrm{~cm}^{3}$; time of contact, $24 \mathrm{~h}$.

$o$-HB, the chelating material containing the DDE moiety, showed higher preference towards the metal loading capacity. This could be explained on the basis of the fact that, in the presence of a negative resonance effect of $-\mathrm{SO}_{2}$-group in the chelating material containing a DDS moiety, the electrons tend to shift in the manner shown in the Scheme 2. This, in turn, decreases the electron density upon the phenolic oxygen atom and consequently the metal coordination capability. However, the metal chelating nature of the chelating materials also depends on the nature of the ligand groups present and their accessibility towards the metal ions. The steric hindrance of the matrix as well as hydrophobic nature of the ligands may also limit the metal complexation process.

Changes in $\mathrm{pH}$ of the medium are one of the most important parameters affecting the preconcentration procedure, which is related to the formation of soluble metal complexes and subsequently their stabilities in aqueous solution. ${ }^{19}$ A series of metal ions, $\mathrm{Cr}^{3+}, \mathrm{Mn}^{2+}$, and $\mathrm{Zn}^{2+}$, were examined in various buffer solutions of pH 1.0 to 8.0 (Fig. 3). In acidic pH (within $\mathrm{pH} 1$-4), the chelating materials showed low metal ion uptake properties due to the protonation of chelating sites in the ligands that inhibit their binding to metal ions. ${ }^{20}$ With increase in $\mathrm{pH}$ of the medium, the metal sorption of the chelating materials increased due to the increase in coordination ability for the formation of phenoxide ion upon phenolic $\mathrm{OH}$-group and due to the increase in basicity of the imine nitrogen atom. The order of metal ion sorption by both the chelating materials was found to be $\mathrm{Zn}^{2+}>\mathrm{Mn}^{2+}>\mathrm{Cr}^{3+}$, indicating that the highest affinity is towards $\mathrm{Zn}^{2+}$ extraction, and the lowest is exhibited for $\mathrm{Cr}^{3+}$. 


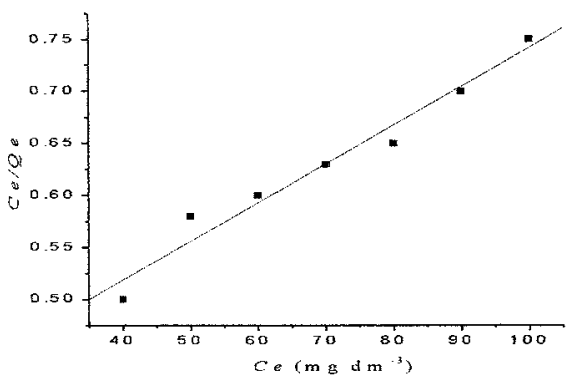

Fig. 4 Verification of Langmuir adsorption isotherm. For chelating material Si-DDE-o-HB: metal ion, $\mathrm{Zn}^{2+}$; time of contact, $24 \mathrm{~h}$; temperature, $28 \pm 2{ }^{\circ} \mathrm{C}$.

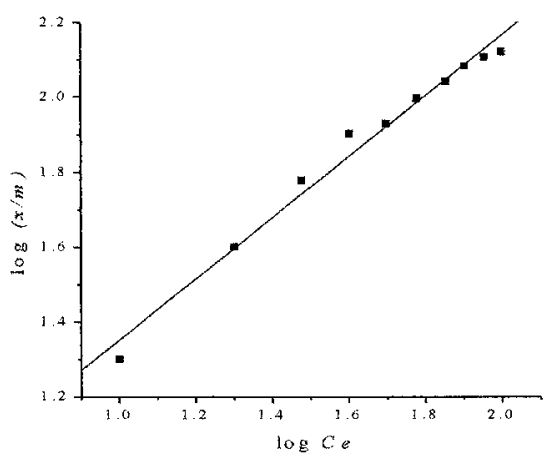

Fig. 5 Verification of Freundlich adsorption isotherm. For chelating material Si-DDE-o-HB: metal ion, $\mathrm{Zn}^{2+}$; time of contact, 24 h; temperature, $28 \pm 2^{\circ} \mathrm{C}$.

We did not attempt to go beyond $\mathrm{pH} 8.0$ due to the observation of precipitation in the medium.

\section{Sorption kinetics}

The effect of metal ion concentration on the uptake behavior of the chelating materials was studied in the concentration range 10 to $100 \mu \mathrm{g} \mathrm{cm}^{-3}$. A leveling effect was noticed at higher concentrations because of saturation of available coordination sites. $^{21}$ The sorption isotherms were evaluated for Langmuir equation and Freundlich adsorption equations..$^{22,23}$ The equation is $C_{\mathrm{e}} / Q_{\mathrm{e}}=1 / Q_{\mathrm{o}} \cdot b+C_{\mathrm{e}} / Q_{\mathrm{o}}$, where $C_{\mathrm{e}}$ is the equilibrium concentration $\left(\mu \mathrm{g} \mathrm{cm} \mathrm{cm}^{-3}\right), Q_{\mathrm{e}}$ is the amount adsorbed at equilibrium, and $Q_{0}$ and $b$ are Langmuir constants related to adsorption capacity and energy of adsorption, respectively. The linear plot of $C_{\mathrm{e}} / Q_{\mathrm{e}}$ versus $C_{\mathrm{e}}$ shows that the adsorption obeys the Langmuir adsorption model (Fig. 4). The correlation coefficient for the linear regression fitting the Langmuir plot was found to be 0.9657 . $Q_{\mathrm{o}}$ and $b$ determined from the Langmuir plot were found to be $270.27 \mu \mathrm{g} \mathrm{g}^{-1}$ of the chelating material and $0.01 \mu \mathrm{g}^{-1}$. The equilibrium parameter $R_{\mathrm{L}}$ is defined by $R_{\mathrm{L}}=1 /\left(1+b C_{\mathrm{o}}\right)$, where $b$ is a Langmuir constant, and $C_{\mathrm{o}}$ is the initial concentration of $\mathrm{Zn}^{2+}$. At two different initial concentration of $\mathrm{Zn}^{2+}$, i.e., 10 and $100 \mathrm{mg} \mathrm{dm}^{-3}$, the $R_{\mathrm{L}}$ values were found to be 0.5 and 0.09 , respectively. The values obtained at two different concentrations lie between 0 and 1 , which indicated a favorable adsorption of $\mathrm{Zn}^{2+}$ onto the chelating material surface (Si-DDE- $o-\mathrm{HB})$. Plotting the Freundlich equation: $\log (x / m)=\log k_{\mathrm{ad}}+1 / n \log C_{\mathrm{e}}$, where, $C_{\mathrm{e}}$ is the equilibrium concentration of the metal ions in $\mu \mathrm{g} \mathrm{cm}^{-3}, m$ is the weight of the chelating materials, $x$ is the quantity of metal ion sorbed by the chelating material in $\mu \mathrm{g}$ and $n$ is the constant.
Table 1 Determination of separation factor at different $\mathrm{pH}$ values of the medium

\begin{tabular}{cccc}
\hline Chelating material & $\mathrm{pH}$ & $\alpha, \mathrm{Zn} / \mathrm{Mn}$ & $\alpha, \mathrm{Zn} / \mathrm{Cr}$ \\
\hline Si-DDE- $o$-HB & 6 & 6.18 & 15.19 \\
& 7 & 7.03 & 30.31 \\
& 8 & 18.92 & 75.78 \\
\hline
\end{tabular}

Amount of chelating material, $0.5 \mathrm{~g}$; time of contact, $24 \mathrm{~h}$.

Table 2 Effect of diverse foreign ions

\begin{tabular}{ccccc}
\hline $\begin{array}{c}\text { Chelating } \\
\text { material }\end{array}$ & $\begin{array}{c}\text { Metal } \\
\text { ion }\end{array}$ & $\begin{array}{c}\text { Conc. of } \\
\text { metal ion// } \\
\mathrm{mg} \mathrm{dm}^{-3}\end{array}$ & $\begin{array}{c}\text { Rec., } \\
\%\end{array}$ & $\begin{array}{c}\text { Rec. in the } \\
\text { presence of mixture } \\
\text { of diverse ion } / \\
20 \mathrm{mg} \mathrm{dm}^{-3} \text { each }\end{array}$ \\
\hline Si-DDE-o-HB & $\mathrm{Zn}^{2+}$ & 20 & 98.4 & 96.2 \\
& $\mathrm{Mn}^{2+}$ & 20 & 98.9 & 95.1 \\
Si-DDS- $o$-HB & $\mathrm{Cr}^{3+}$ & 20 & 98.3 & 95.9 \\
& $\mathrm{Zn}^{2+}$ & 20 & 98.5 & 94.1 \\
& $\mathrm{Mn}^{2+}$ & 20 & 98.4 & 95.2 \\
& $\mathrm{Cr}^{3+}$ & 20 & 97.3 & 94.7 \\
\hline
\end{tabular}

Amount of chelating material, $0.5 \mathrm{~g}$; time of contact, $24 \mathrm{~h}$; each reading was an average of three close/concordant values.

a. RSD factor varies between $0.35-0.52 \%$.

b. RSD factor varies between $0.32-1.16 \%$.

A plot of $\log (x / m)$ versus $\log C_{\mathrm{e}}$ (Fig. 5) is linear and the constants $k_{\text {ad }}$ and $n$ are found to be 3.446 and 1.227 , respectively. The value, $1<n<10$, indicates the favorable sorption of $\mathrm{Zn}^{2+}$ onto the chelating material. The correlation coefficient for the isotherm found to be 0.9831 , indicating a better fit for the experimental data than the Langmuir plot.

\section{Competitive sorption behavior}

Selective extraction or separation of a given metal ion in the presence of other metal ions is controlled mainly by the following factors: (i) the nature of the donating sites in the ligand that are capable of selective bonding to the central metal ion; (ii) the nature of the metal ion to be selectively extracted; and (iii) the hydrogen ion concentration. The chelating material (Si-DDE-o-HB) was utilized to study the competitive sorption of $\mathrm{Zn}^{2+} / \mathrm{Mn}^{2+}, \mathrm{Zn}^{2+} / \mathrm{Cr}^{3+}$ from dilute aqueous solution at different $\mathrm{pH}$ values of the medium. The higher affinity towards $\mathrm{Zn}^{2+}$ ions in a competitive environment could be due to the preferentially binding with the positionally active (non-sterically hindered) oxygen atom present in the salicylaldehyde Schiff base ligand. The separation factor $\alpha$ (used as a measure of the chromatographic separation process) is presented by, $\alpha=D_{1} / D_{2}$, where $D_{1}$ and $D_{2}$ are the distribution coefficients of the two metal ions. The separation factors $\alpha$ for separation of $\mathrm{Zn}^{2+}$ containing binary mixtures at $\mathrm{pH}$ values of $6.0,7.0$ and 8.0 are shown in Table 1 .

\section{Effect of diverse foreign ions}

The analytical preconcentration procedure for trace heavy metal ions can be strongly influenced due to matrix constituents: e.g., alkali and alkaline earth elements. Therefore, the effect of matrix constituents was examined in the presence of sulfate, nitrate, chloride, $\mathrm{NH}_{4}^{+}, \mathrm{Na}^{+}, \mathrm{K}^{+}, \mathrm{Mg}^{2+}$ and $\mathrm{Ca}^{2+}$, which are common ionic species in natural water. A high concentration of studied species was chosen to magnify their interference effect. The results (Table 2) indicated that the 
Table 3 Effect of flow rate in column operation study

\begin{tabular}{ccccc}
\hline $\begin{array}{c}\text { Chelating } \\
\text { material }\end{array}$ & $\mathrm{pH}$ & $\begin{array}{c}\text { Metal ion/ } \\
20 \mathrm{mg} \mathrm{dm}^{-3}\end{array}$ & $\begin{array}{c}\text { Flow rate/ } \\
\mathrm{cm}^{3} \mathrm{~min}^{-1}\end{array}$ & Sorption, \% \\
\hline Si-DDE- 0 -HB & 7.5 & $\mathrm{Zn}^{2+}$ & 0.5 & 80.4 \\
& & & 1.0 & 65.3 \\
& & & 1.5 & 50.2 \\
Si-DDS- 0 -HB & 7.5 & $\mathrm{Zn}^{2+}$ & 0.5 & 24.3 \\
& & & 1.0 & 34.0 \\
& & & 1.5 & 10.2 \\
& & & 2.0 & $\mathrm{BQL}^{\mathrm{a}}$ \\
\hline
\end{tabular}

a. BQL: below quantitative limit.

matrix ions had little effect on the uptake capacity of the metal ions. The effects of anions like citrate and oxalate were also examined in case of Si-DDE-o-HB to discover the effect of organic species upon the recovery of $\mathrm{Zn}^{2+}$ only $\left(20 \mathrm{mg} \mathrm{dm}^{-3}\right)$. It was found that the presence of citrate and oxalate reduces the metal recovery by $82 \%$ and $85 \%$, respectively. The effects of some other organic species are currently under investigation.

\section{Metal ion uptake sorption and desorption studies using column} technique

The results of column operation studies are furnished in Table 3. Due to the higher rate of sorption of $\mathrm{Zn}^{2+}$ by the chelating material, as observed in batch operation study, $\mathrm{Zn}^{2+}$ was chosen for the column operation study. The studies were carried out at a $\mathrm{pH}$ value of 7.5. For Si-DDE-o-HB, it was observed that, at $\mathrm{pH} 7.5$ and $0.5 \mathrm{~cm}^{3} \mathrm{~min}^{-1}$, the flow rate of the solution, the column successfully retained nearly $80 \%$ of the $\mathrm{Zn}^{2+}$ ions. The flow rate was varied between $0.5-2.0 \mathrm{~cm}^{3} \mathrm{~min}^{-1}$ and sorption of metal ions found to decrease substantially with increasing flow rate. At higher flow rates, the contact time of metal ions with the column materials was shorter. This may be attributed to the increase in sorption process with increasing residence time of the solute in the column. We did not go below the flow rate of $0.5 \mathrm{~cm}^{3} \mathrm{~min}^{-1}$ due to the extended time consumption in analysis.

Desorption of metal ions from the packed column was also attempted with $\geq 1.0 \mathrm{~mol} \mathrm{dm}{ }^{-3} \mathrm{HNO}_{3}$ solution. The above $\mathrm{Zn}^{2+}$ loaded column was eluted with dilute $\mathrm{HNO}_{3}\left(20 \mathrm{~cm}^{3}\right.$, > $1.0 \mathrm{~mol}$ $\mathrm{dm}^{-3}$ concentration); the flow of the eluting agent was controlled $\left(0.5 \mathrm{~cm}^{3} \mathrm{~min}^{-1}\right)$ using the stopcock. Nearly $75-80 \%$ of the loaded metal ions could be successfully eluted from the loaded columns in the first cycle. With second and third elution with $\mathrm{HNO}_{3}$ solution, almost $100 \%$ removal of the loaded cation from the column was possible. Increasing the flow rate of the eluting agent, however, decreases the percentage of elution. The preconcentration factor was found to be 66.2 , with breakthrough volume of $15 \mathrm{~cm}^{3}$. Still higher preconcentration factors may be achieved by decreasing the elution volume.

The stability and reusability of the chelating materials was also tested by the following method. The $\mathrm{Zn}^{2+}$ was sorbed and desorbed on $1.0 \mathrm{~g}$ of the chelating material for three times. After three cycles, the equilibration changes by $3-4 \%$ only. The sorption capacity of the chelating material which was stored for 2 months under ambient condition has been found to be practically unchanged.

Preconcentration of heavy metal ions from natural tap water sample

Drinking water samples (spiked separately with $\mathrm{Zn}^{2+}, \mathrm{Mn}^{2+}$, $\mathrm{Cr}^{3+}\left(0.5-1.0 \mathrm{mg} \mathrm{dm}{ }^{-3}\right)$, were prepared. Then $500 \mathrm{mg}$ of
Table 4 Analysis of drinking water samples

\begin{tabular}{ccccc}
\hline $\begin{array}{c}\text { Chelating } \\
\text { material }\end{array}$ & $\begin{array}{c}\text { Metal } \\
\text { ion }\end{array}$ & $\begin{array}{c}\text { Metal ion } \\
\text { added/ } \\
\mathrm{mg} \mathrm{dm}^{-3}\end{array}$ & $\begin{array}{c}\text { Metal ion } \\
\text { found/ } \\
\mathrm{mg} \mathrm{dm}^{-3}\end{array}$ & $\begin{array}{c}\text { Recovery, } \\
\%\end{array}$ \\
\hline Si-DDE-o-HB & $\mathrm{Zn}^{2+}$ & 0 & 0.54 & - \\
& & 0.5 & 1.01 & 97.2 \\
& & 1.0 & 1.48 & 96.2 \\
& $\mathrm{Mn}^{2+}$ & 0 & 0.34 & - \\
& & 0.5 & 0.81 & 96.3 \\
& $\mathrm{Cr}^{3+}$ & 0 & 1.30 & 97.0 \\
& & 0.5 & 0.49 & - \\
& & 1.0 & 0.98 & 98.0 \\
& & & &
\end{tabular}

chelating material Si-DDE- $o$-HB was added. These mixtures were stirred for $3 \mathrm{~h}$, and then filtered; the unsorbed metal ions were determined by AAS (Table 4). The result showed that in all the cases the recoveries of metal ions was found to be $>$ $96 \%$.

\section{Conclusions}

Two new chelating materials (Si-DDE-o-HB and Si-DDS-o$\mathrm{HB}$ ) were synthesized by modifying the activated silica gel phase. The materials were characterized and tested for the preconcentration of metal ions like $\mathrm{Zn}^{2+}, \mathrm{Mn}^{2+}$ and $\mathrm{Cr}^{3+}$ in batch and column techniques with variation in parameters in competitive and non-competitive conditions. The saturation values for the uptake of $\mathrm{Zn}^{2+}$ and $\mathrm{Mn}^{2+}$ by both the chelating materials were obtained in about $30 \mathrm{~min}$, whereas the sorption of $\mathrm{Cr}^{3+}$ required nearly $3 \mathrm{~h}$. The sorption capacity of Si-DDE-o$\mathrm{HB}$ was found to be higher than that of the Si-DDS-o-HB, this could be explained on the basis of negative resonance effect in DDS unit. The order of metal sorption for both the chelating materials was found to be $\mathrm{Zn}^{2+}>\mathrm{Mn}^{2+}>\mathrm{Cr}^{3+}$. Sorption capacities of similar types of silica base immobilized metal chelate Schiff bases were also evaluated extensively by some other authors for metal ions like $\mathrm{Fe}^{3+}, \mathrm{Ni}^{2+}, \mathrm{Cu}^{2+}, \mathrm{Zn}^{2+}, \mathrm{Cd}^{2+}$ and $\mathrm{Pb}^{2+}{ }^{24}$ The reactivity of metal ion sorption was discussed in the light of bulkiness, orientation of immobilized chelate, and participation of azomethene nitrogen and phenolic hydroxyl group oxygen atoms. In the present case, the preconcentration factor for the elution of $\mathrm{Zn}^{2+}$ using a column technique was found to be 66.2 with a breakthrough volume of $15 \mathrm{~cm}^{3}$. The column experiment suggested that the material Si-DDE-o-HB can find applications for the metal sorption from dilute aqueous solution.

\section{Acknowledgements}

We are thankful to CDRI, Lucknow, for providing the spectra and to Bangalore Institute of Technology, Bangalore, for BET surface area studies. One of the authors (R. K. Dey) is thankful to University Grants Commission (UGC), New Delhi, for providing financial support for the project work (Grant No. F1232/04).

\section{References}

1. R. K. Iler, "The Chemistry of Silica, Solubility, 
Polymerization, Colloid and Surface Properties and Biochemistry", 1979, Wiley Interscience, New York.

2. P. Liang and X. Chen, Anal. Sci., 2005, 21, 1185.

3. J. F. Biernat, P. Konieczk, B. Tarbet, J. S. Bradshow, and R. U. Izatt, in "Separation and Purification Methods", 1994, Vol. 23, No. 2, Marcel Dekker, New York, 77.

4. T. Seshadri and H. J. Haupt, Anal. Chem., 1988, 60, 47.

5. M. E. Mahmoud, M. M. Osman, and M. E. Amer, Anal. Chim. Acta, 2000, 415, 33.

6. M. E. Mahmoud and E. M. Soliman, Talanta, 1997, 44, 15.

7. R. G. Pearson, J. Am. Chem. Soc., 1963, 85, 3533.

8. P. K. Jal, S. Patel, and B. K. Mishra, Talanta, 2004, 62, 1005.

9. A. G. S. Prado and C. Airoldi, Anal. Chim. Acta, 2001, 432, 201.

10. R. Kocjan and S. Prezeszlakowski, Talanta, 1992, 39, 63.

11. M. E. Mahmoud and G. A. Gohar, Talanta, 2000, 51, 77.

12. S. Blain and P. Trèguer, Anal. Chim. Acta, 1995, 308, 425.

13. K. Ueno and A. E. Martell, J. Phys. Chem., 1955, 59, 998.

14. C. M. Che and W. K. Cheng, J. Chem. Soc., Chem. Commun., 1986, 1443.

15. M. Calligaris and R. Randaccis, in "Comprehensive
Coordination Chemistry", ed. W. Wilkinson, R. D. Gillard, and Mc Cleverty, 1987, Vol. 2, Chap. 20, Oxford, London.

16. D. A. Atwood, Coord. Chem. Rev., 1997, 165, 267.

17. L. S. Clesceri, A. E. Greenberg, and R. R. Trussell, "Standard Methods for the Examination of Water and Waste Water", 17th ed., 1989, American Public Health Association Publications, Washington.

18. P. K. Jal, R. K. Dutta, M. Sudarshan, A. Saha, S. N. Bhattacharyya, S. N. Chintalapudi, and B. K. Mishra, Talanta, 2001, 55, 233.

19. Ş. Tokalioğlu, T. Oymak, and Ş. Kartal, Anal. Chim. Acta, 2004, 511, 255.

20. E. M. Soliman, Anal. Lett., 1998, 31, 299.

21. T. I. Tikhomirova, V. I. Fadeeva, G. V. Kudryavtesev, P. N. Nesterenko, V. M. Ivanov, A. T. Savitchev, and N. S. Smirnova, Talanta, 1991, 38, 267.

22. I. Langmuir, J. Am. Chem. Soc., 1918, 40, 1361.

23. D. M. Ruthven, "Principles of Adsorption and Adsorption Processes", 1984, Wiley, New York.

24. E. M. Soliman, M. E. Mahmoud, and S. A. Ahmed, Talanta, 2001, 54, 243. 